\title{
Intrauterine growth restriction: distribution, risk factors, management of labour and outcome
}

\author{
Diana Andzane ${ }^{1 *}$, Igor Gapatins ${ }^{1}$, Anna Miskova ${ }^{1,2,3}$ \\ ${ }^{1}$ Department of Obstetrics \& Gynaecology, Riga Stradins University, Riga, Latvia \\ ${ }^{2}$ Department of Obstetrics \& Gynaecology, Riga Maternity Hospital, Riga, Latvia \\ ${ }^{3}$ Department of Obstetrics \& Gynaecology, Infertility Clinic iVF Riga, Riga, Latvia
}

Received: 02 June 2015

Accepted: 10 July 2015

\section{*Correspondence:}

Dr. Diana Andzane,

E-mail: andzane.diana@gmail.com

Copyright: $\odot$ the author(s), publisher and licensee Medip Academy. This is an open-access article distributed under the terms of the Creative Commons Attribution Non-Commercial License, which permits unrestricted non-commercial use, distribution, and reproduction in any medium, provided the original work is properly cited.

\begin{abstract}
Background: The development of Intrauterine growth restriction (IUGR) determines maternal, fetal and placental factors. Many of these factors are preventable. There is still no enough developed effective pregnancy and labour management tactics that could protect both mother and child from the unintended consequences.

Methods: The research was made in Riga Maternity Hospital. In the research there were included pregnant women who gave birth neonates with weight under 10th percentile (IUGR group) as well there was compiled the control group. The weight of neonates was evaluated using the percentile scales - Intrauterine Growth Curves based on US data.

Results: According to the criteria, in the IUGR group were included 209 pregnant women and in the control group was the same number of patients. In the IUGR group mothers discharged from the hospital one day later than it was in the control group both after vaginal delivery $(4.0 \pm 1.5$ vs. $3.3 \pm 1.0, \mathrm{p}<0.0001)$ and after caesarean $(5.6 \pm 1.5$ vs. 4.5 $\pm 1.0, \mathrm{p}=0.0001)$. Comparing the evaluations after Apgar scale after spontaneous birth, induced labour and caesarean it was discovered that there is no statistically significant difference.

Conclusions: IUGR negatively affect not just the fetus but also the mother and this is the reason why she should stay in the hospital for a longer period due to the child or experience the caesarean.
\end{abstract}

Keywords: Intrauterine growth restriction, IUGR risk factors, Management of labour

\section{INTRODUCTION}

IUGR clinically diagnoses if the weight of the foetus is below the 10th percentile of appropriate gestational time and gender, ${ }^{1-3}$ which determined in sequential measurements. ${ }^{4}$

Incidence of IUGR singleton pregnancies in 2009 was 3$7 \%{ }^{4,5}$ It is important to note that decreasing perinatal mortality in Europe (year 20045.5 vs. year 20103.8 per 1000 alive children), increases the number of children that born alive and whose weight is less than 2500 grams (6.3\% in 2004 vs. $6.5 \%$ in 2010). ${ }^{6}$ One of the main reasons for the birth of a child whose weight is less than
2500 grams is a premature birth. As World Health Organization (WHO) informs, the number of premature births has increased during the last twenty years. WHO as well as other authors link this statistics with the changes in risk factors such as frequent use of assisted reproductive technologies, increasing maternal age and obesity. ${ }^{6-8}$ The development of IUGR determines maternal, foetal and placental factors. Many of these factors are preventable (smoking, alcohol abuse, infections, preeclampsia, obesity, assisted multiple pregnancy).

There is still no enough developed effective pregnancy and labour management tactics that could protect both mother and child from the unintended consequences. That 
is why this theme was chosen for the research. The aim of the research is to comprehend the influence of IUGR on the foetus and pregnant woman as well as the avoidance possibilities of the adverse consequences.

\section{METHODS}

\section{Trial design and participants}

During the retrospective research were examined data of patients in Riga Maternity Hospital for the year 2013. In the research were included pregnant women who gave birth to the neonates with the weight below 10th percentile (IUGR group). In the control group were included pregnant women who gave birth neonates with the weight that corresponds to $11-89^{\text {th }}$ percentile. For better understanding of the studied parameters dependence from IUGR weight, IUGR group was divided into 3 subgroups:

1) The weight of neonates corresponds to $\leq 3$ percentile (accidental definition for severe IUGR).

2) The weight of neonates corresponds to 5 - 4th percentile (accidental definition for moderate IUGR).

3) The weight of neonates corresponds to $10-6$ th percentile (accidental definition for easy IUGR).

\section{Outcomes}

The weight of neonates was estimated using the percentile scales - Intrauterine Growth Curves based on U.S. data.

\section{Statistical methods}

The obtained data were statistically processed using MS Excel and SPSS programs. Statistical analysis of study data was performed by two-tailed Student's test and $\chi^{2}$ test. They were considered to be statistically believable if $\mathrm{p}<0.05$.

\section{RESULTS}

In 2013, 209 pregnant women were included in the IUGR group because they were appropriate for the criteria. In the control group was included the same number of pregnant women. IUGR incidence in the population is 3.2 $\%$.

The easy IUGR subgroup consisted of 113 neonates, in the moderate IUGR subgroup were 39 neonates and in the severe IUGR subgroup were included 57 neonates.

As shown in Table 1, the gestational period statistically does not differ from the control group neither in the subgroups nor in the IUGR group in general. In the subgroups of the IUGR group the weight of neonates corresponded to 8.1 percentile $(2731 \pm 287 \mathrm{~g}), 4.5$ percentile $(2572 \pm 440 \mathrm{~g})$ and 1.5 percentile $(2294 \pm 386 \mathrm{~g})$. After the evaluating the coherence between the weight and length of neonates, it was discovered that with the reduction of the weight percentile falls also the length percentile. It means that symmetrical IUGR frequency increases and asymmetrical IUGR prevalence decreases.

The evaluation of neonates by Apgar score statistically differed ( $\mathrm{p}$ value from 0.012 to $<0.0001$ ) both after 1 minute and after 5 minutes between the subgroups of IUGR and control group. The evaluation after 1 minute was following $\leq 3$ percentile in the subgroup 7.79 points, 5.-4. proc. $-7.54,10$.-6. proc. -7.57 , in the IUGR group total 7.54 and in the control group 7.77 points, but after 5 minutes respectively there were $\leq 3$ percentile in the subgroup 8.53 points, 5.-4. proc. $-8.56,10 .-6$. proc. 8.59 , in the IUGR group total -8.57 and in the control group 8.83 points. The fewer percentiles correspond to weight of neonates; the lower is the evaluation by Apgar score. As shown in Table 2, comparing the evaluations by Apgar score after the spontaneous delivery, induced delivery and Caesarean operation, the main reason for which was not acute foetal distress, it was revealed that there is no statistically difference $(\mathrm{p}=0.2)$, only after the induced delivery the indicators are better than after the Caesarean operation.

Table 1: Characteristics of newborn.

\begin{tabular}{|llll|}
\hline Characteristic & $\begin{array}{l}\text { IUGR } \\
\text { group }\end{array}$ & $\begin{array}{l}\text { Control } \\
\text { group }\end{array}$ & p value \\
\hline $\begin{array}{l}\text { Weeks of pregnancy } \\
\text { (week) }\end{array}$ & 39.3 & 38.9 & 0.057 \\
\hline Birth weight (g) & 2582 & 3241 & 0.315 \\
\hline $\begin{array}{l}\text { Percentile of birth } \\
\text { weight }\end{array}$ & 5.6 & 47.3 & $<0,0001$ \\
\hline Birth height (cm) & 48.8 & 51.4 & 0.590 \\
\hline $\begin{array}{l}\text { Percentile of birth } \\
\text { height }\end{array}$ & 34.7 & 70.9 & 0.480 \\
\hline
\end{tabular}

Table 2: Comparison of Apgar score after spontaneous delivery, induced delivery and Caesarean operation.

\begin{tabular}{|llll|}
\hline & $\begin{array}{l}\text { Spontaneous } \\
\text { delivery }\end{array}$ & $\begin{array}{l}\text { Induced } \\
\text { delivery }\end{array}$ & $\begin{array}{l}\text { Caesarean } \\
\text { operation }\end{array}$ \\
\hline Apgar score & 7.43 & 7.68 & 7.13 \\
\hline $\begin{array}{l}\text { Spontaneous } \\
\text { delivery, p value }\end{array}$ & - & 0.200 & 0.217 \\
\hline $\begin{array}{l}\text { Induced } \\
\text { delivery, p value }\end{array}$ & - & - & 0.012 \\
\hline
\end{tabular}

Figure 1 shows the determination of IUGR in gestation. In the control group were also nine foetuses. Before their birth there was IUGR $(4.3 \%)$ but when they were born, they did not correspond to diagnostic criteria. Acute fetal distress more often developed in the IUGR group, what is 
more its frequency increased when the weight percentile of foetus decreased (Figure 2).

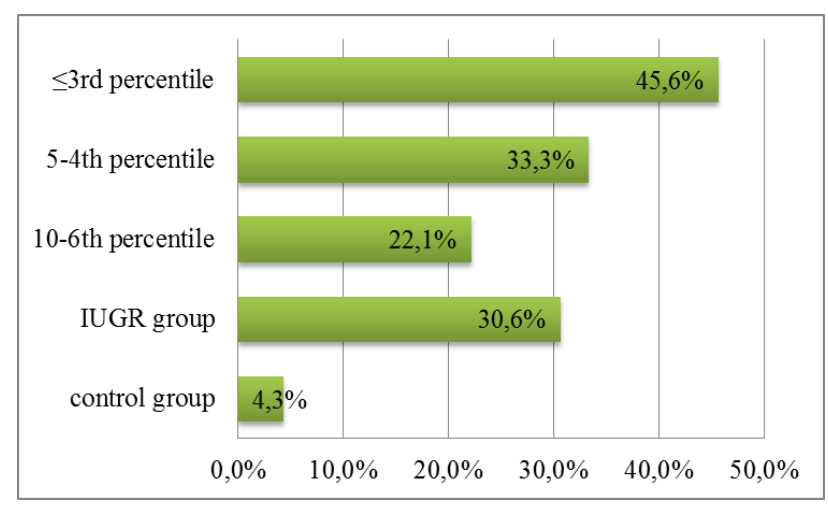

Figure 1: IUGR detection rate.

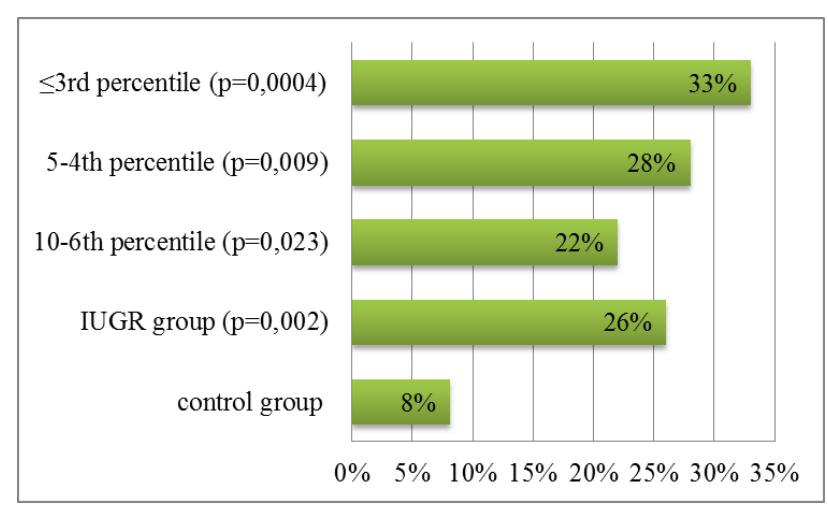

Figure 2: Incidence of acute fetal distress.

Maternal characteristics were examined in Table 3. In the group of IUGR, mothers were discharged from the hospital one day later than in the control group both after the vaginal delivery, and after the Caesarean operation.

Table 3: Description of myomas in CM cases.

\begin{tabular}{|c|c|c|c|c|}
\hline \multicolumn{2}{|c|}{ Characteristic } & $\begin{array}{l}\text { IUGR } \\
\text { group }\end{array}$ & $\begin{array}{l}\text { control } \\
\text { group }\end{array}$ & p value \\
\hline Age & & 28.1 & 29.1 & 0.706 \\
\hline \multirow{2}{*}{$\begin{array}{l}\text { Duration } \\
\text { of } \\
\text { hospital } \\
\text { stay(day) }\end{array}$} & $\begin{array}{l}\text { after vaginal } \\
\text { delivery }\end{array}$ & 4.0 & 3.4 & $<0,0001$ \\
\hline & $\begin{array}{l}\text { after } \\
\text { Caesarean } \\
\text { operation }\end{array}$ & 5.6 & 4.5 & $<0,0001$ \\
\hline \multicolumn{2}{|c|}{ Body mass index $\left(\mathrm{kg} / \mathrm{m}^{2}\right)$} & 22.1 & 23.0 & 0.052 \\
\hline
\end{tabular}

During the research were found various IUGR risk factors (Figure 3). Intrauterine infection was more common in the IUGR group, in addition its incidence increased when percentile of foetal weight decreased (10 - 6th perc. $-9.7 \%, 5$ - 4th perc. $-17.9 \% \leq 3$. perc. - 19 , $3 \%$ ). Abnormalities of the umbilical cord (vasculitis, true knot of the umbilical cord, wrong attachment of the umbilical cord) were severe for 6 foetuses in the IUGR group $(10.5 \%)$, moderate were for 3 foetuses in the IUGR group (7.7\%), easy abnormalities had 3 foetuses in the IUGR group (2.7\%), but in the control group abnormalities had just one foetus $(0.5 \%)$. In the IUGR group 5 severe pregnant women $(8,8 \%, \mathrm{p}=0,001)$ used drugs or alcohol, in the other IUGR subgroups there were not such pregnant women and that is why total incidence in the IUGR group was lower $(2,4 \%, \mathrm{p}=0,25)$, in its turn there were just two pregnant women $(1 \%)$ in the control group who used drugs or alcohol.

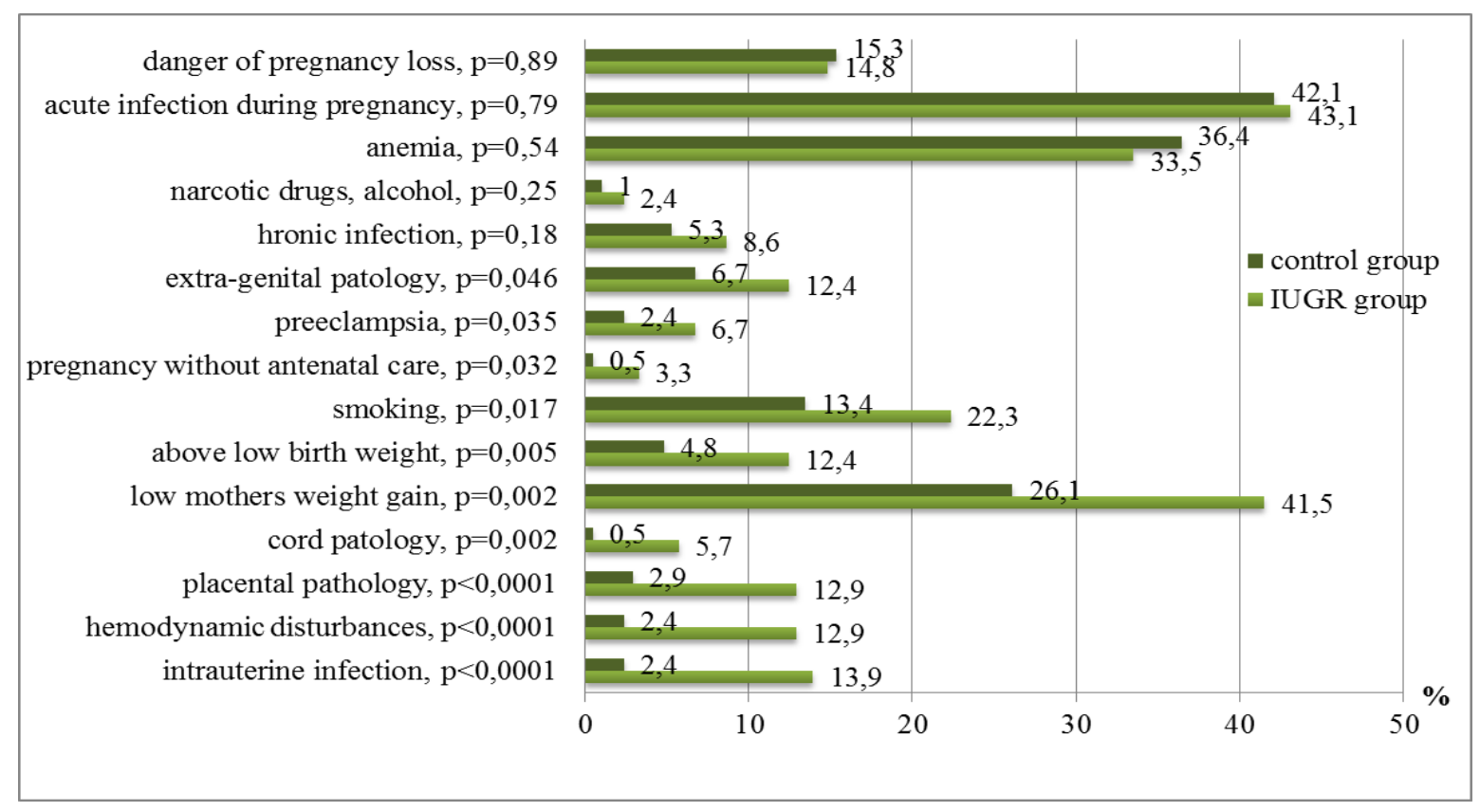

Figure 3: IUGR risk factors. 
There were seven pregnant women (3.3\%) without antenatal care in the IUGR group, what is more, three of them were in the severe IUGR subgroup, but in the control group was just one pregnant woman $(0.5 \%)$. In the IUGR group were more mothers with different pathologies such as hypothyroidism, thyrotoxicosis, bronchial asthma, primary arterial hypertension. Statistically credible in the IUGR group were diagnosed more often hemodynamic disturbances, pre-eclampsia and other placental pathology that included placental conditions such as infarction foci, haemorrhage, and vasculitis.

During the pregnancy increased the weight of mothers. It evaluation was dependent on mother's body mass index (BMI) before pregnancy. If mother's BMI was $<18.5$ $\mathrm{kg} / \mathrm{m}^{2}$, it was considered that weight growth is not enough if she took less than $1.7 \mathrm{~kg}$. During the pregnancy the weight which was less than $11.4 \mathrm{~kg}$ was considered as low, if BMI 18.5 to $24.9 \mathrm{~kg} / \mathrm{m}^{2}$, less than $6.8 \mathrm{~kg}$, if BMI 25 to $29.9 \mathrm{~kg} / \mathrm{m}^{2}$, and less than 5 , if BMI above $30 \mathrm{~kg} /$ $\mathrm{m}^{2} .{ }^{9}$ As a result, $41.5 \%$ of pregnant women in the IUGR group had a small weight during the pregnancy, but in the control group small weight had just $26.1 \%$ of pregnant women.

The average BMI in the both groups were not different (IUGR group 22.1, control group 23.0, p=0,052).

In all groups and subgroups equally often pregnant women gave birth spontaneously (IUGR gr. 63.2\% vs. control gr. $65.6 \%, \mathrm{p}=0.83)$. On the contrary, in all subgroups of IUGR statistically more often were done and rarely planned acute Caesarean operation but in the control group it was vice versa (Figure 4). Totally, in the IUGR group $26.3 \%$ of pregnant women did Caesarean operation.

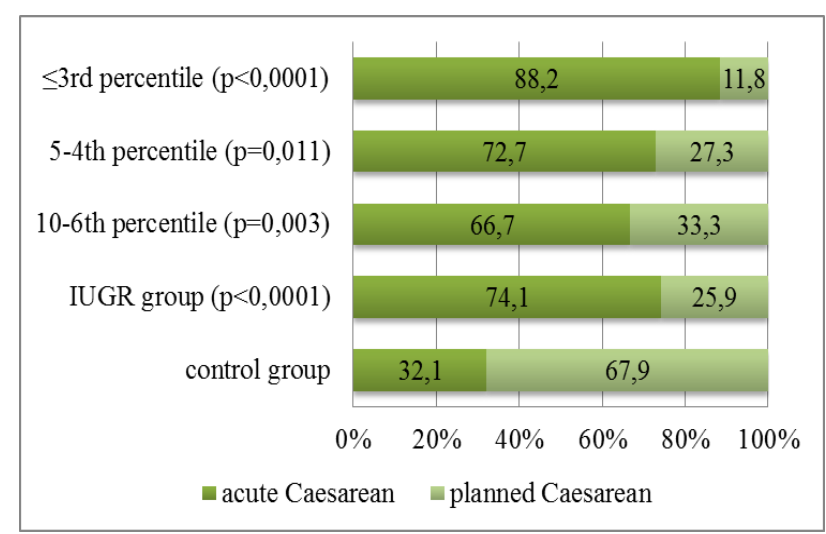

Figure 4: Comparison of acute and planned caesarean ratio.

\section{DISCUSSION}

In our research the incidence of IUGR corresponds to the average statistical indicators in other literal sources, ${ }^{4,5}$ but it should be taken into account that the research was made just within one hospital. IUGR was recognized for a small number of foetuses $(30.6 \%)$. Because of imprecise diagnostics there was not provided a sufficient careful observation of these pregnant women and their foetuses. Somewhere else there is mentioned that approximately in $75 \%$ of all cases, IUGR remains unrecognized until the birth and diagnosed in retrospect but the detection rate of low risk pregnancies is about $15 \% .{ }^{10}$ Early diagnostics of IUGR until 16th gestational week today is one of the main research directions. ${ }^{11}$ Our recommendation would be to work out the recommendations for more precise diagnostics of IUGR in Latvia that could allow assessing the dynamics of fetal growth.

Similarly to the research of Dr. N. Vedmedovska that was made in Latvia during years 2007 - 2009, in our research statistically credible were confirmed several IUGR risk factors - smoking, maternal extra genital pathology, preeclampsia. In the same way there were not confirmed such risk factors as anaemia, threat of pregnancy interruption, use of drugs or alcohol during the pregnancy although somewhere else these factors are confirmed in the determination of IUGR risk group. ${ }^{11}$ Determination of risk factors is easy and cheap method so they should be detected and diverted as early as possible. It was found that weak woman's fatness before pregnancy does not affect the development of IUGR; it just determines the necessity of additional weight admission during the pregnancy. However Sharifzadeh et al. in the research found a positive correlation between SGA and low maternal BMI before pregnancy. ${ }^{12}$

In the previous Latvian research, the average gestational time among the foetuses in IUGR was much smaller (36.3 weeks), but the caesarean was carried out more frequently. In our study, the average gestational time was 39.3 weeks. This difference could be explained with iatrogenic prematurity creation, carrying out caesarean for the faster resolution of pregnancy.

From the 90 s of this century gradually increases the number of caesareans because theoretically the latest technologies will be able to provide more favourable environment for the neonates. ${ }^{13}$ Our results show that choosing the right tactics for the pregnancy with IUGR, preference is given to temporizing tactics and further vaginal delivery but there is no reason for the faster resolution of pregnancy. In our research, caesarean was carried out in $26.3 \%$ cases of pregnancies with IUGR, which is a good indicator.

It is confirmed that the heavier is IUGR, the more frequently develops the acute fetal distress and this is the reason for acute caesarean. For the timely diagnosis of acute distress, it should be provided regular and longterm CTG with ST segment analysis and hemodynamic monitoring. ${ }^{13,14}$ 
Funding: No funding sources

Conflict of interest: None declared

Ethical approval: The study was approved by the Riga

Stradins University Ethics committee

\section{REFERENCES}

1. Fabre E, González de Agüero R, de Agustín JL, Ezquerra A. Intrauterine growth restriction: concept and epidemiology. In: Kurjak A, Chervenak FA, eds. Textbook of Perinatal Medicine. 2nd ed. London, UK: Informa;2006:1238-46.

2. Ernst SA, Reeske A, Spallek J, Petersen K, Brand T, Zeeb H. Care-related factors associated with antepartal diagnosis of intrauterine growth restriction: a case-control study. BMC Pregnancy Childbirth. 2014;14(1):371.

3. Andzane D, Miskova A, Polukarova S, Gapatins I. Expectant management of intrauterine growth restriction pregnancy: perinatal outcome. Int $\mathrm{J}$ Reprod Contracept Obstet Gynecol. 2015;4:312-5.

4. Stanisic Chou T, Toohey JS. Fetal Growth Disorders. In: Di Saia PJ, Chaudhuri G, Giudice LC, Moore TR, Porto M, Smith LH, eds. Women's Health Review: A Clinical Update in Obstetrics-Gynecology. Philadelphia, PA: Elsevier Saunders. 2012; 97-100.

5. Romo A, Carceller R, Tobajas J. Intrauterine growth retardation (IUGR): epidemiology and etiology. Pediatr Endocrinol Rev. 2009;6(3):332-6.

6. European Perinatal Health Report. Health and Care of Pregnant Women and Babies in Europe in 2010.

7. Johansson S, Villamor E, Altman M, Bonamy AK, Granath F, Cnattingius S. Maternal overweight and obesity in early pregnancy and risk of infant mortality: a population based cohort study in Sweden. BMJ. 2014;2(349):6572.
8. Xu K, Wang YA, Li Z, Lui K, Sullivan EA. Risk factors associated with preterm birth among singletons following assisted reproductive technology in Australia $2007 \_2009 \_$a populationbased retrospective study. BMC Pregnancy Childbirth. 2014;7;14(1):406.

9. Institute of Medicine Sets New Guidelines for Weight Gain During Pregnancy. Medscape. Available http://www.medscape.com/viewarticle/703514. Accessed 1 June 2015.

10. Figueras F, Gardosi J. Intrauterine growth restriction: new concepts in antenatal surveillance, diagnosis, and management. Am J Obstet Gynecol. 2011;204(4):288-300.

11. Albu AR, Anca AF, Horhoianu VV, Horhoianu IA. Predictive factors for intrauterine growth restriction. J Med Life. 2014;7(2):165-71.

12. Sharifzadeh F, Kashanian M, Jouhari S, Sheikhansari N. Relationship between pre-pregnancy maternal BMI with spontaneous preterm delivery and birth weight. J Obstet Gynaecol. 2014;10:1-4.

13. Carrera JM, Figueras F, Devesa R, Mallafré J. Management of small-for-gestational-age fetuses: antenatal and intrapartum strategies. In: Kurjak A, Chervenak FA, eds. Textbook of Perinatal Medicine. 2nd ed. London, UK: Informa; 2006:1296-312.

14. Harkness UF, Mari G. Diagnosis and management of intrauterine growth restriction. Clin Perinatol. 2004;31:743-64.

Cite this article as: Andzane D, Gapatins I, Miskova A. Intrauterine growth restriction: distribution, risk factors, management of labour and outcome. Int J Reprod Contracept Obstet Gynecol 2015;4:1117-21. 